\title{
A matrix model for valuing anesthesia service with the resource-based relative value system
}

This article was published in the following Dove Press journal:

Journal of Multidisciplinary Healthcare

8 October 2014

Number of times this article has been viewed

\author{
David R Sinclair ${ }^{\prime}$ \\ David A Lubarsky' \\ Michael MVigoda' \\ David J Birnbach' \\ Eric A Harris' \\ Vicente Behrens' \\ Richard E Bazan' \\ Steve MWilliams' \\ Kristopher Arheart ${ }^{2}$ \\ Keith A Candiotti' \\ 'Department of Anesthesiology, \\ Perioperative Medicine and Pain \\ Management, ${ }^{2}$ Department of \\ Public Health Sciences, Division of \\ Biostatistics, University of Miami \\ Miller School of Medicine, Miami, FL, \\ USA
}

Correspondence: David R Sinclair Department of Anesthesiology, Perioperative Medicine and Pain Management, University of Miami Hospital, I400 NW I2th Ave, Suite 3I55, Miami, FL 33।36, USA

$\mathrm{Tel}+\mathrm{I} 954376 \mathbf{1 2 9 0}$

$\mathrm{Fax}+\mathrm{I} 3053253990$

Email dsinclair@med.miami.edu
Background: The purpose of this study was to propose a new crosswalk using the resource-based relative value system (RBRVS) that preserves the time unit component of the anesthesia service and disaggregates anesthesia billing into component parts (preoperative evaluation, intraoperative management, and postoperative evaluation). The study was designed as an observational chart and billing data review of current and proposed payments, in the setting of a preoperative holing area, intraoperative suite, and post anesthesia care unit. In total, 1,195 charts of American Society of Anesthesiology (ASA) physical status 1 through 5 patients were reviewed. No direct patient interventions were undertaken.

Results: Spearman correlations between the proposed RBRVS billing matrix payments and the current ASA relative value guide methodology payments were strong $(r=0.94-0.96, P<0.001$ for training, test, and overall). The proposed RBRVS-based billing matrix yielded payments that were $3.0 \% \pm 1.34 \%$ less than would have been expected from commercial insurers, using standard rates for commercial ASA relative value units and RBRVS relative value units. Compared with current Medicare reimbursement under the ASA relative value guide, reimbursement would almost double when converting to an RBRVS billing model. The greatest increases in Medicare reimbursement between the current system and proposed billing model occurred as anesthetic management complexity increased.

Conclusion: The new crosswalk correlates with existing evaluation and management and intensive care medicine codes in an essentially revenue neutral manner when applied to the market-based rates of commercial insurers. The new system more highly values delivery of care to more complex patients undergoing more complex surgery and better represents the true value of anesthetic case management.

Keywords: payment reform, billing, crosswalk

\section{Introduction}

A new era of physician payment reform in the USA was ushered in by the Patient Protection and Affordable Care Act of 2010, creating incentives through cost saving and quality initiatives for multispecialty physician groups, health systems, hospitals, and independent practice associations to better coordinate patient care. The law seeks to reduce health care costs through incentives to reduce unnecessary care by adding value-based, quality, and cost modifiers to the resource-based relative value scale (RBRVS), which is used to bill for the evaluation and management of patients. ${ }^{1}$ Accountable Care Organizations (ACOs) are an integral part of the Patient Protection and Affordable Care Act and consist of providers who are accountable for achieving quality improvements in the care of a defined population of patients and for reductions 
in the rate of spending growth. ${ }^{1}$ ACOs seek to decrease total costs of a given population through a mechanism of capitated payments by Medicare, and private insurers are mimicking these capitation models and bundled payments for episodes of care for particular diseases and diagnosis related groups. Of relevance to both academic and private practice anesthesiologists, ACOs may involve a variety of provider configurations, ranging from academic anesthesiology practices in a hospital-based system to private anesthesiology practices in an integrated delivery system. As physicians join together and hospitals align with physician groups, a common billing system that reflects the efforts of anesthesiologists will facilitate our inclusion. While the information assessed during each patient encounter would remain unchanged, the evaluation and management code for each encounter would be based upon the current RBRVS. To better model the RBRVS used by all other physicians, the individual components of the anesthesia visit (preoperative level of care, intraoperative anesthetic management complexity, length of time spent attending to the patient, and postoperative level of care) would be considered separately. The American Society of Anesthesiologists (ASA) relative value guide (RVG) is the current payment system, and its unit values are assigned according to Current Procedural Terminology (CPT) descriptive terms. The ASA RVG numerical codes and modifiers differ greatly from unit values of the RBRVS, and accepted methods for cross-linking the ASA RVG to the current RBRVS do not exist.

The relationship between the usual customary and reasonable rate (UCR) and what Medicare (MCR) pays is very different for anesthesia compared with all other specialties. ${ }^{2}$ A common billing system could benefit anesthesiologists, whose work effort using ASA relative value units (RVU) is greatly undervalued by current CMS reimbursement methodologies. ${ }^{3}$ Why do anesthesiologists have a different relative value system for reimbursement? Projections of decreased reimbursement from implementing a common RBRVS and the exclusion of the customary time component of the anesthesia service led anesthesiologists to successfully lobby in 1989 for the preservation of reimbursement by the methodology of the ASA RVG. ${ }^{4-6}$ The ASA RVU measures work input according to the sum of base, time, and modifier units. The base units reflect the complexity of each preoperative evaluation and the difficulty in planning and executing the anesthetic. The time units reflect the total time of oversight of the care of the patient, and the modifier units add value to the base units. The sum of the units is multiplied by a conversion factor to generate the anesthesiologist's professional fee.
There is no inherent reason to eliminate time while incorporating standard RBRVS descriptors of services provided, as many time-based codes continue to exist in the RBRVS.

We hypothesized that we could build a crosswalk, using an RBRVS billing system for anesthesia services, which would easily map to current ASA RVG methodology. The model's construction should essentially be revenue neutral, from the perspective of market-based valuation, and be unconstrained by government price setting. In addition, the model's design should value advanced decision-making and account for the complexity of care delivery associated with significant comorbidities and management dilemmas, which are not primary drivers of reimbursement in the current ASA RVG but are primary drivers for payment in the RBRVS system.

\section{Materials and methods Data source}

We analyzed 1,195 cases performed at a broad spectrum of anesthetic locations within two large health systems, one private and one public, ie, the University of Miami health system and the Jackson health system. We included all sites where anesthesia was delivered and a fee-for-service bill was generated by the Department of Anesthesiology at the University of Miami, with the exception of obstetrics. Facilities included University of Miami Hospital, a 560-bed private academic tertiary hospital, University of Miami Sylvester Cancer Center, a subspecialty hospital with 40 beds, Anne Bates Leach Eye Hospital, a primarily outpatient eye, otolaryngology, and orthopedic facility, an outpatient eye facility in West Palm Beach, Jackson Memorial Hospital, a 1,500-bed adult and pediatric county tertiary care hospital, and Jackson South Hospital, a 260bed community hospital that was absorbed by the county hospital system and that continued to be staffed primarily by private nonacademic surgeons. Cases were performed from October 25, 2010 through October 31, 2010, and the IDX (Burlington, VT) billing system database in the Department of Anesthesiology at the University of Miami was used to analyze each case approximately 6 months after the date of service along with copies of each preoperative evaluation and case record.

For each case we noted the patient's age (for use with pediatric coding), comorbidities, intensive care unit (ICU) disposition (preoperatively and postoperatively), outpatient versus inpatient status, and emergent versus elective nature of the operation. Outpatients were defined as those who were discharged home on the same day of surgery, whereas 
inpatients included hospitalized patients or those admitted to the hospital following their surgery.

\section{Reclassification of evaluation and management codes with ASA physical status}

The "matrix plan" was developed with a discussion of 300 randomly assigned charts, in a group fashion among at least three authors with more than 15 years of experience. The initial analysis was performed on the first 300 charts received from the medical records department. Each case was analyzed for their ASA physical status (PS) modifiers, and with the CPT definitions of evaluation and management codes present. There was a consistent pattern of mapping that allowed the group to define prospectively the patient's level of visit (LOV), a measure of anesthesia perioperative workup and case management decision-making. For example, if a patient had each of three coexisting morbidities that each would have yielded an ASA PS 3, their LOV would be higher than the same patient with a single comorbidity, yielding an ASA PS 3 .

The number of comorbidities and their correlation with the degree of medical decision-making in patient management were considered and mapped to an appropriate evaluation and management complexity (see Table 1 for mapping). Comorbidities were defined as diseases involving body systems, and the number and severity of comorbidities were considered by senior clinical anesthesiologists with more than 15 years of experience. Each ASA PS category and patient type was mapped to an appropriate evaluation and management code, according to the Healthcare Common Procedure Coding System in the 2011 CPT manual, which reflected the complexity of decision-making (see Table 2 ). ${ }^{7}$

\section{Preoperative assessment encounters}

The first preoperative evaluation and management of an outpatient, same-day admission patient, and inpatient

Table I ASA physical status and level of visit

\begin{tabular}{lll}
\hline ASA PS & Comorbidities $(\mathbf{n})$ & LOV \\
\hline $\mathrm{I}$ & 0 & $\mathrm{I}$ \\
2 & $\mathrm{I}$ or 2 & 2 \\
2 & $\geq 3$ & 3 \\
3 & $\mathrm{I}$ or 2 & 3 \\
3 & $\geq 3$ & 4 \\
4 & $\mathrm{I}$ & 4 \\
4 & $\geq 2$ & 5 \\
5 & $\mathrm{I}$ & 5 \\
\hline
\end{tabular}

Abbreviations: ASA, American Society of Anesthesiologists; PS, physical status; LOV, level of visit.
Table 2 Evaluation and management codes and ASA physical status score

\begin{tabular}{|c|c|c|c|}
\hline $\begin{array}{l}\text { HCPCS } \\
\text { E\&M code }\end{array}$ & Description & $\begin{array}{l}\text { Proposed } \\
\text { application }\end{array}$ & $\begin{array}{l}\text { ASA PS/ } \\
\text { patient type }\end{array}$ \\
\hline 99201 & $\begin{array}{l}\text { Office/outpatient visit, } \\
\text { new }\end{array}$ & $\begin{array}{l}\text { Outpatient, } \\
\text { preoperative }\end{array}$ & ASA PS I \\
\hline 99202 & $\begin{array}{l}\text { Office/outpatient visit, } \\
\text { new }\end{array}$ & $\begin{array}{l}\text { Outpatient, } \\
\text { preoperative }\end{array}$ & ASA PS 2 \\
\hline 99203 & $\begin{array}{l}\text { Office/outpatient visit, } \\
\text { new }\end{array}$ & $\begin{array}{l}\text { Outpatient, } \\
\text { preoperative }\end{array}$ & ASA PS 3 or 6 \\
\hline 99204 & $\begin{array}{l}\text { Office/outpatient visit, } \\
\text { new }\end{array}$ & $\begin{array}{l}\text { Outpatient, } \\
\text { preoperative }\end{array}$ & $\begin{array}{l}\text { ASA PS } 3^{3} \\
\text { or } 4\end{array}$ \\
\hline 99211 & $\begin{array}{l}\text { Office/outpatient visit, } \\
\text { established }\end{array}$ & $\begin{array}{l}\text { Outpatient } \\
\text { PACU care }\end{array}$ & ASA PS I \\
\hline 99212 & $\begin{array}{l}\text { Office/outpatient visit, } \\
\text { established }\end{array}$ & $\begin{array}{l}\text { Outpatient } \\
\text { PACU care }\end{array}$ & ASA PS 2 \\
\hline 99213 & $\begin{array}{l}\text { Office/outpatient visit, } \\
\text { established }\end{array}$ & $\begin{array}{l}\text { Outpatient } \\
\text { PACU care }\end{array}$ & ASA PS 3 or 6 \\
\hline 99214 & $\begin{array}{l}\text { Office/outpatient visit, } \\
\text { established }\end{array}$ & $\begin{array}{l}\text { Outpatient } \\
\text { PACU care }\end{array}$ & $\begin{array}{l}\text { ASA PS } 3^{3} \\
\text { or } 4\end{array}$ \\
\hline 99221 & Initial hospital care & $\begin{array}{l}\text { Inpatient, } \\
\text { preoperative }\end{array}$ & ASA PS I or 2 \\
\hline 99222 & Initial hospital care & $\begin{array}{l}\text { Inpatient, } \\
\text { preoperative }\end{array}$ & ASA PS 3 or 6 \\
\hline 99223 & Initial hospital care & $\begin{array}{l}\text { Inpatient, } \\
\text { preoperative }\end{array}$ & $\begin{array}{l}\text { ASA PS } 3^{3}, \\
4,5\end{array}$ \\
\hline 99231 & $\begin{array}{l}\text { Subsequent } \\
\text { hospital care }\end{array}$ & $\begin{array}{l}\text { Inpatient } \\
\text { PACU care }\end{array}$ & ASA PS I or 2 \\
\hline 99232 & $\begin{array}{l}\text { Subsequent } \\
\text { hospital care }\end{array}$ & $\begin{array}{l}\text { Inpatient } \\
\text { PACU care }\end{array}$ & ASA PS 3 or 6 \\
\hline 99233 & $\begin{array}{l}\text { Subsequent } \\
\text { hospital care }\end{array}$ & $\begin{array}{l}\text { Inpatient } \\
\text { PACU care }\end{array}$ & $\begin{array}{l}\text { ASA PS } 3^{3}, \\
4,5\end{array}$ \\
\hline 99291 & Critical care, first hour & Initial time & Adult \\
\hline 99292 & $\begin{array}{l}\text { Critical care, additional } \\
30 \text { minutes }\end{array}$ & $\begin{array}{l}\text { Subsequent } \\
\text { time }\end{array}$ & Adult \\
\hline 99466 & $\begin{array}{l}\text { Critical care transport } \\
<2 \text { years, first } \\
30-74 \text { minutes }\end{array}$ & Initial time & Pediatric \\
\hline 99467 & $\begin{array}{l}\text { Critical care transport, } \\
<2 \text { years, additional } \\
30 \text { minutes }\end{array}$ & $\begin{array}{l}\text { Subsequent } \\
\text { time }\end{array}$ & Pediatric \\
\hline 99354 & Prolonged service, office & Simple time & ASA PS Ior 2 \\
\hline 99355 & $\begin{array}{l}\text { Prolonged service, office } \\
\text { additional } 30 \text { minutes }\end{array}$ & Simple time & ASA PS I or 2 \\
\hline
\end{tabular}

Abbreviations: HCPCS, Healthcare Common Procedure Coding System; E\&M, evaluation and management; PACU, post anesthesia care unit; ASA, American Society of Anesthesiologists; PS, physical status; $3^{3}$, three or more comorbidities.

was considered a "new patient" visit, extending the well established rule from the CPT manual of treating each emergency room visit as a new patient encounter. In a similar way to a new patient encounter in the emergency room, a full preoperative patient assessment is indicated prior to each procedure or operation. Outpatients were associated with an "office" visit while same day admission patients or inpatients were considered "hospital care" visits. Each LOV was paired with a CPT code that corresponded to a similar depth of 
history-taking, physical examination, and medical decisionmaking (see Tables 3-5). Since the CPT manual defined different codes for inpatients and outpatients, each LOV and corresponding CPT code varied according to when the service was performed (preoperative or postoperative) and the type of patient being managed (outpatient or same-day admission inpatient). All emergency patients were coded at the inpatient level, even if the procedure was outpatient, given the added complexity of care treating those cases as if they were provided in a procedure room of an emergency department in a hospital.

\section{Postoperative assessment encounters}

Postoperative evaluation and management of outpatients, same-day admissions, and inpatients were considered "established" patient visits, consistent with subsequent care flowing from the initial preoperative evaluation and knowledge of intraoperative care. "Established hospital care" codes were used for same-day admissions and inpatients. Each LOV was associated with a CPT code that reflected a similar depth of evaluation and management as reflected in the history-taking, physical examination, and medical decision-making (see Table 6). All patients admitted to the ICU and transferred to the care of a critical care physician following surgery received no postoperative care charges in the RBRVS anesthesia billing system proposed.

\section{Reclassification of base units and LOV with anesthetic management complexity} Intraoperative patient care

Base units relate to the complexity of the anesthetic management and include all of the usual anesthesia services, such as complexity of preoperative evaluation, intraoperative decision-making, and room preparation directly related to the conduct of the case, but not taking into specific account the health status of the patient, which is solely accounted for in the current system by assignment of the ASA PS. Using the well established ranking of case difficulty within

Table 3 Outpatient preoperative assessment and CPT codes

\begin{tabular}{lllll}
\hline LOV & $\begin{array}{l}\text { CPT } \\
\text { code }\end{array}$ & History & Examination & $\begin{array}{l}\text { Medical } \\
\text { decision-making }\end{array}$ \\
\hline I & 99201 & $\begin{array}{l}\text { Problem- } \\
\text { focused }\end{array}$ & $\begin{array}{l}\text { Problem- } \\
\text { focused }\end{array}$ & Straightforward \\
2 & 99202 & Expanded focus & Expanded focus & Straightforward \\
3 & 99203 & Detailed & Detailed & Low complexity \\
4 & 99204 & Comprehensive & Comprehensive & $\begin{array}{l}\text { Moderate } \\
\text { complexity }\end{array}$ \\
\hline
\end{tabular}

Abbreviations: LOV, level of visit; CPT, Current Procedural Terminology.
Table 4 Same day admission/inpatient preoperative assessment and CPT codes

\begin{tabular}{|c|c|c|c|c|}
\hline LOV & $\begin{array}{l}\text { CPT } \\
\text { code }\end{array}$ & History & Examination & $\begin{array}{l}\text { Medical } \\
\text { decision-making }\end{array}$ \\
\hline I & 99221 & Detailed & Detailed & Low complexity \\
\hline 2 & 99221 & Detailed & Detailed & nplexity \\
\hline 3 & 99222 & Comprehensive & Comprehensive & $\begin{array}{l}\text { Moderate } \\
\text { complexity }\end{array}$ \\
\hline 4 & 99223 & Comprehensive & Comprehensive & High complexity \\
\hline 5 & 99223 & Comprehensive & Comprehensive & High complexity \\
\hline
\end{tabular}

Abbreviations: LOV, level of visit; CPT, Current Procedural Terminology.

the ASA RVG, five categories were created according to the number of base units $(\leq 6,7-9,10-13,14-19$, and $\geq 20)$. The sum of the base unit category (1-5) and our newly mapped LOV (1-5) generated a number from 2-10 that senior reviewers all agreed reflected on the physical and mental preparation required, decision-making involved, and stress likely to be encountered in administering the anesthetic, known as the anesthetic management complexity (AMC) level (see Table 7). ${ }^{8}$ AMC levels 2-4, 5-8, and 9-10 were designated low, high, and critical, respectively. All emergency cases presenting with a $\mathrm{LOV} \geq 3$ were assigned the high AMC level rate, given the increased complexity of decision-making for emergency cases. Three hundred randomly chosen cases and many hypothetical examples were categorized according to AMC by a group of at least three senior experienced clinicians to validate the level of complexity assigned to cases. ${ }^{9,10}$

\section{Derivation of payment schedule}

The actual expected Medicare reimbursement for all cases was calculated at a conversion factor of US $\$ 24.96 /$ unit, * the Medicare conversion factor (from the Centers for Medicare and Medicaid Services 2010 and 2011 Physician Fee Schedule) for Miami, FL (during the billing period), and the current expected private reimbursement for all cases was calculated

Table 5 Same day admission/inpatient preoperative assessment and CPT codes

\begin{tabular}{lllll}
\hline LOV & $\begin{array}{l}\text { CPT } \\
\text { code }\end{array}$ & History & Examination & $\begin{array}{l}\text { Medical } \\
\text { decision-making }\end{array}$ \\
\hline 1 & 99231 & $\begin{array}{l}\text { Problem- } \\
\text { focused }\end{array}$ & $\begin{array}{l}\text { Problem- } \\
\text { focused }\end{array}$ & Low complexity \\
2 & 99231 & $\begin{array}{l}\text { Problem- } \\
\text { focused }\end{array}$ & $\begin{array}{l}\text { Problem- } \\
\text { focused }\end{array}$ & Low complexity \\
3 & 99232 & $\begin{array}{l}\text { Extended } \\
\text { focus }\end{array}$ & $\begin{array}{l}\text { Extended } \\
\text { focus }\end{array}$ & $\begin{array}{l}\text { Moderate } \\
\text { complexity }\end{array}$ \\
4 & 99233 & Detailed & Detailed & High complexity \\
5 & 99233 & Detailed & Detailed & High complexity \\
\hline
\end{tabular}

Abbreviations: LOV, level of visit; CPT, Current Procedural Terminology. 
Table 6 Outpatient postoperative assessment and CPT codes

\begin{tabular}{|c|c|c|c|c|}
\hline LOV & $\begin{array}{l}\text { CPT } \\
\text { code }\end{array}$ & History & Examination & $\begin{array}{l}\text { Medical } \\
\text { decision-making }\end{array}$ \\
\hline I & 99211 & None & None & None \\
\hline 2 & 99212 & $\begin{array}{l}\text { Problem- } \\
\text { focused }\end{array}$ & $\begin{array}{l}\text { Problem- } \\
\text { focused }\end{array}$ & Straightforward \\
\hline 3 & 99213 & Extended focus & Extended focus & Low complexity \\
\hline 4 & 99214 & Detailed & Detailed & $\begin{array}{l}\text { Moderate } \\
\text { complexity }\end{array}$ \\
\hline 5 & 99215 & Comprehensive & Comprehensive & High complexity \\
\hline
\end{tabular}

Abbreviations: LOV, level of visit; CPT, Current Procedural Terminology.

at a conversion factor of $\$ 67.02 /$ unit, the lowest mean commercial conversion factor in 2010 for the Southern region of the USA. ${ }^{11}$ The proposed Medicare reimbursement under our new RBRVS system was generated using the new billing matrix at Medicare rates outlined in the 2010 National Physician Fee Schedule Relative Value File. ${ }^{12}$ Each proposed Medicare reimbursement was calculated as the sum of the Medicare reimbursements for each pre/postoperative LOV and the product of the Medicare RBRVS RVU rate and the number of time units.

The payment schedule for the preoperative assessment LOV, anesthetic management complexity rating, and postoperative assessment LOV was derived from the 2010 National Physician Fee Schedule Relative Value File for Medicare rates. Each Medicare rate (total RVU $\times$ conversion factor) was associated with a Level 1 Healthcare Common Procedure Coding System code and a proposed application (see Table 8). We used an average commercial rate of $125 \%$ (1.25 times) the Medicare rate, the CMS goal for UCR/MCR rates, which is within the well established range of $119 \%-133 \%$ of Medicare fees for surgical and diagnostic procedure codes. ${ }^{13}$ The Medicare reimbursement rates for outpatient and inpatient preoperative assessment are listed on Table 8. Reimbursement rates for postoperative assessments were less than the corresponding preoperative rates (see Table 9).

Each intraoperative patient encounter was conservatively regarded as similar in intensity to a prolonged office visit. Table 10 outlines the Medicare payment schedule for low and

Table 7 Matrix for calculating anesthetic management complexity level

\begin{tabular}{llllll}
\hline & LOV I & LOV 2 & LOV 3 & LOV 4 & LOV 5 \\
\hline I-6 base units & 2 & 3 & 4 & 5 & 6 \\
7-9 base units & 3 & 4 & 5 & 6 & 7 \\
I0-13 base units & 4 & 5 & 6 & 7 & 8 \\
I4-19 base units & 5 & 6 & 7 & 8 & 9 \\
$\geq 20$ base units & 6 & 7 & 8 & 9 & 10 \\
\hline
\end{tabular}

Abbreviation: LOV, level of visit.
Table 8 Preoperative assessment payment schedule and LOV

\begin{tabular}{|c|c|c|c|}
\hline HCPCS & Description & MCR (US \$) & Proposed application \\
\hline 99201 & $\begin{array}{l}\text { Office/outpatient } \\
\text { visit, new }\end{array}$ & 26.34 & Outpatient LOV I \\
\hline 99202 & $\begin{array}{l}\text { Office/outpatient } \\
\text { visit, new }\end{array}$ & 49.79 & Outpatient LOV 2 \\
\hline 99203 & $\begin{array}{l}\text { Office/outpatient } \\
\text { visit, new }\end{array}$ & 76.13 & Outpatient LOV 3 \\
\hline 99204 & $\begin{array}{l}\text { Office/outpatient } \\
\text { visit, new }\end{array}$ & 129.88 & Outpatient LOV 4 \\
\hline 99221 & Initial hospital care & 99.58 & Inpatient LOV 1 and 2 \\
\hline 99222 & Initial hospital care & 135.66 & Inpatient LOV 3 \\
\hline 99223 & Initial hospital care & 199.16 & Inpatient LOV 4 and 5 \\
\hline
\end{tabular}

Abbreviations: HCPCS, Healthcare Common Procedure Coding System; MCR, Medicare Rate; LOV, level of visit.

high AMC level cases and pediatric cases. For the Medicareinsured patient, a low AMC level (equal to an extended office visit) was valued at $\$ 18.18 /$ unit ( $\$ 90.92 /$ initial 75 minutes) for the first five units (ie, 75 minutes $=$ five 15-minute units) and $\$ 44.74 /$ unit thereafter (\$89.48/each subsequent 30 minutes) for each additional unit beyond five. Each high AMC level was deemed equivalent to ICU care and valued at $\$ 55.20$ / unit (\$220.80/initial 60 minutes) for the first four units and $\$ 55.18 /$ unit (\$110.36/each subsequent 30 minutes) for each additional unit beyond four. A low AMC level pediatric case was valued at $\$ 50.94 /$ unit (\$254.72/initial 75 minutes) and \$58.99/units (\$117.98/each subsequent 30 minutes) for each additional unit beyond five units. A critical AMC level was valued at twice the high AMC level rates. See Table 11 for a summary of intraoperative Medicare reimbursement.

All ICU patients were deemed to be high AMC (billed equivalently to ICU care) if they were admitted postoperatively to the ICU, regardless of other assessments, as the intraoperative

Table 9 Postoperative assessment payment schedule and LOV

\begin{tabular}{|c|c|c|c|}
\hline HCPCS & Description & $\begin{array}{l}\text { MCR } \\
(\$)\end{array}$ & $\begin{array}{l}\text { Proposed } \\
\text { application }\end{array}$ \\
\hline 99211 & $\begin{array}{l}\text { Office/outpatient visit, } \\
\text { established }\end{array}$ & 9.38 & Outpatient LOV I \\
\hline 99212 & $\begin{array}{l}\text { Office/outpatient visit, } \\
\text { established }\end{array}$ & 25.62 & Outpatient LOV 2 \\
\hline 99213 & $\begin{array}{l}\text { Office/outpatient visit, } \\
\text { established }\end{array}$ & 50.87 & Outpatient LOV 3 \\
\hline 99214 & $\begin{array}{l}\text { Office/outpatient visit, } \\
\text { established }\end{array}$ & 77.57 & Outpatient LOV 4 \\
\hline 99215 & $\begin{array}{l}\text { Office/outpatient visit, } \\
\text { established }\end{array}$ & 109.32 & Outpatient LOV 5 \\
\hline 99231 & Subsequent hospital care & 38.97 & Inpatient LOV I and 2 \\
\hline 99231 & Subsequent hospital care & 71.08 & Inpatient LOV 3 \\
\hline 99233 & Subsequent hospital care & 101.74 & Inpatient LOV 4 and 5 \\
\hline
\end{tabular}

Abbreviations: HCPCS, Healthcare Common procedure Coding System; MCR, Medicare rate; LOV, level of visit. 
Table 10 Anesthetic complexity management payment schedule source

\begin{tabular}{|c|c|c|c|}
\hline HCPCS & Description & $\begin{array}{l}\text { MCR } \\
(\$)\end{array}$ & $\begin{array}{l}\text { Proposed } \\
\text { application }\end{array}$ \\
\hline 99354 & $\begin{array}{l}\text { Prolonged office service, } \\
\text { first } 74 \text { minutes }\end{array}$ & 90.92 & AMC level: low \\
\hline 99355 & $\begin{array}{l}\text { Prolonged office service, } \\
\text { additional } 30 \text { minutes }\end{array}$ & 89.48 & AMC level: low \\
\hline 99291 & Critical care, first 60 minutes & 220.80 & AMC level: high \\
\hline 99292 & Critical care, additional 30 minutes & 110.76 & AMC level: high \\
\hline 99466 & $\begin{array}{l}\text { Critical care transport, }<2 \text { years, } \\
30-74 \text { minutes }\end{array}$ & 254.72 & Pediatric \\
\hline 99467 & $\begin{array}{l}\text { Critical care transport, }<2 \text { years, } \\
\text { additional } 30 \text { minutes }\end{array}$ & 117.98 & Pediatric \\
\hline
\end{tabular}

Abbreviations: HCPCS, Healthcare Common Procedure Coding System; MCR, Medicare rate; AMC, anesthesia management complexity.

maintenance of care requiring constant attendance of a professional was considered as rigorous as the preoperative or postoperative care being provided in the hospital.

The Certified Registered Nurse Anesthetist service component of the anesthesia bill was not directly addressed. Within this model, it was expected that during medical direction, Certified Registered Nurse Anesthetists would be reimbursed at a level of a physician or advanced nurse practitioner providing a prolonged office service, and anesthesiologists would bill anything beyond that, including perioperative management fees (see Table 10), as appropriate for the work performed and oversight provided. During medical supervision, the anesthesiologist would be expected to charge for physician standby services according to the corresponding Medicare rate of $\$ 30.67$ per unit ( $\$ 61.33 / 30$ minutes; see Tables 11 and 12$)$. There were no such fees included in this particular analysis as all services were under medical direction of a care team.

\section{Application of matrix and payment schedule}

To compare current reimbursement using the ASA RVG with the payments under this new RBRVS system, actual

Table II Anesthesia management complexity level and unit Medicare rates

\begin{tabular}{lll}
\hline Proposed application & $\$$ per base unit & $\begin{array}{l}\text { \$ per additional } \\
\text { I5-minute } \\
\text { intervals }\end{array}$ \\
\hline Low AMC level & $\$ 18.18$ (first 5 units) & $\$ 44.74$ \\
High AMC level & $\$ 55.20$ (first 4 units) & $\$ 55.18$ \\
Critical AMC level & $\$ 110.40$ (first 4 units) & $\$ 110.36$ \\
Low AMC level (pediatric) & $\$ 50.94$ (first 5 units) & $\$ 58.99$ \\
Anesthesiologist standby & $\$ 30.67$ & $\$ 30.67$ \\
\hline
\end{tabular}

Abbreviations: AMC, Anesthesia Management Complexity; HCPCS, Healthcare Common Procedure Coding System.
Table I 2010 National physician fee schedule relative value file

\begin{tabular}{llll}
\hline HCPCS & Description & MCR (\$) & $\begin{array}{l}\text { Proposed } \\
\text { application }\end{array}$ \\
\hline 99027 & Out-of-hospital & 0 & $\begin{array}{l}\text { On call service } \\
\text { CRNA cases with }\end{array}$ \\
99360 & Physician standby & 61.33 (each & $\begin{array}{l}\text { CRN "on call” } \\
\end{array}$ \\
\hline
\end{tabular}

Abbreviations: CRNA, certified registered nurse anesthetist; HCPCS, Healthcare Common Procedure Coding System; MCR, Medicare rate; MD, medical doctor.

expected versus new anesthesia RBRVS billing system Medicare payments for low, high, and critical complexities were analyzed. The average expected payment for commercial reimbursement, calculated as the product of the actual RVU per case and the average conversion factor for southeastern commercial insurers, $\$ 67.02$, was compared with the proposed reimbursement at 1.25 times the average Medicare rate for Miami, FL, USA.

One case with incomplete data was excluded from the analysis. To test the robustness of the matrix algorithm, we divided the 1,194 cases in the entire set into a training set consisting of 300 sampled cases and a test set comprising the remaining 894 cases. To further test the validity of the model, the set was assessed with three additional sets of 300 randomly chosen cases and a test set of the remaining 894. Statistics were computed for the costs calculated by the matrix and standard methods for the training and test data sets as well as the entire data set. Using SAS version 9.3 (SAS Institute Inc., Cary, NC, USA), we computed descriptive statistics, calculated Spearman correlations, and performed the signed rank test.

\section{Results}

The original dataset contained 1,195 cases. One case with incomplete data was excluded from the analysis. Table 13 summarizes specific demographic data from the IDX billing system database including ASA PS, ICU disposition, and emergency status. Surgical procedures were nonemergent

Table I 3 IDX database: patient status and intensive care unit disposition

\begin{tabular}{ll}
\hline Parameter & Percent \\
\hline ASA PS I & 10.54 \\
ASA PS II & 53.81 \\
ASA PS III & 27.20 \\
ASA PS IV & 8.03 \\
ASA PS V & 0.42 \\
ICU preoperative & 1.17 \\
ICU postoperative & 6.19 \\
Emergency & 4.45 \\
\hline
\end{tabular}

Abbreviations: ASA, American Society of Anesthesiologists; PS, physical status; ICU, intensive care unit. 
95.5\% of the time, and $53.8 \%$ of patients were ASA PS 2 . Patients received preoperative and postoperative ICU monitoring $1.2 \%$ and $6.2 \%$ of the time, respectively. The relative distribution of AMC levels and LOV are outlined on Table 14. A low anesthetic management complexity and a perioperative LOV 2 were present $76.9 \%$ and $47.3 \%$ of the time, respectively.

We have shown that the descriptive statistics gave similar medians for both the training and test sets as well as the overall set (see Table 15). Spearman correlations between matrix and standard costs were strong $(r=0.94-0.96, P<0.001$ for training, test, and overall). Signed rank tests resulted in significant differences between the matrix and standard in all three sets. The median differences were very similar and indicated that the standard was significantly higher than the matrix ( $P<0.001$ for all three sets). Very similar results were achieved when the procedure was repeated four times (see Table 15).

Within our large health care systems, the average Medicare reimbursement doubled using the new billing matrix compared with current reimbursements. The average projected payments (using the ASA RVG at the \$24.96/unit conversion factor) and proposed Medicare reimbursements (using the proposed billing matrix) were $\$ 414.53$ and $\$ 865.72$, respectively (see Table 16 ). The $\$ 865.72$ calculated using an RBRVS system included average preoperative evaluation, intraoperative management, and postoperative evaluation payments of $\$ 88.22, \$ 737.33$, and $\$ 40.16$, respectively (see Table 16). The average expected commercial reimbursement, according to the ASA RVG at an average conversion factor for commercial insurers (\$67.02) was $\$ 1,114.25$. This was only $3.0 \% \pm 1.34 \%$ greater than the new RBRVS-based billing matrix, which generated an average commercial reimbursement of $\$ 1,082.15$ using a rate of 1.25 times the RBRVS RVU. However, the distribution of payments among low, high, and critical complexity cases for all payers in the new

Table 14 Level of visit and anesthetic management complexity level

\begin{tabular}{ll}
\hline Parameter & Percent \\
\hline LOV I & 10.54 \\
LOV 2 & 47.32 \\
LOV 3 & 29.84 \\
LOV 4 & 7.27 \\
LOV 5 & 4.93 \\
Low AMC level & 76.99 \\
High AMC level & 12.92 \\
Critical AMC level & 1.09 \\
\hline Abbreviations: AMC, anesthetic management complexity; LOV, level of visit.
\end{tabular}

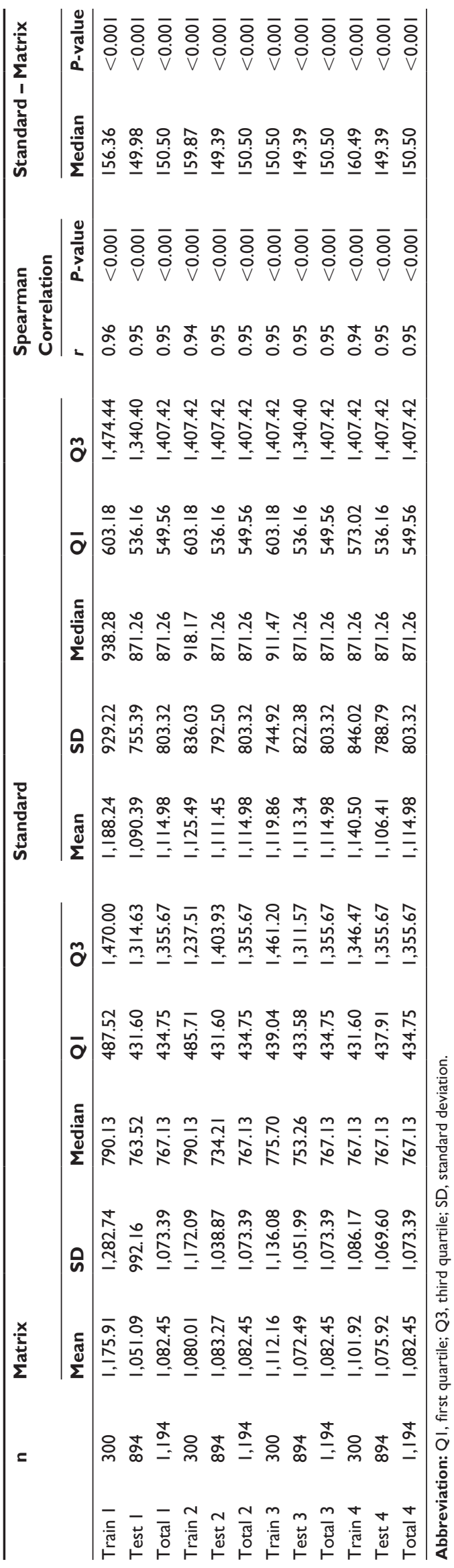


Table 16 Average payments

\begin{tabular}{ll}
\hline Parameter & $\begin{array}{l}\text { Average } \\
\text { payments (\$) }\end{array}$ \\
\hline Actual total Medicare & 414.53 \\
Proposed at Medicare rate & 865.72 \\
Preoperative evaluation & 88.22 \\
Intraoperative management & 737.33 \\
Postoperative evaluation & 40.16 \\
Current expected at lowest private rate & $1,114.25$ \\
Proposed at commercial rate & $1,082.15$ \\
Actual low & 365.50 \\
Actual high & 543.53 \\
Actual critical & $1,690.21$ \\
Proposed low & 608.23 \\
Proposed high & $1,509.91$ \\
Proposed critical & $6,085.28$ \\
\hline
\end{tabular}

system was significantly different $(P<0.001, P<0.001$, and $P=0.002$, respectively) from actual payments for those cases. Payments for low complexity cases were $14.87 \% \pm 1.38 \%$ lower, and proposed payments for high and critical complexity cases were $12.76 \% \pm 1.09 \%$ and $48.55 \% \pm 12.11 \%$ higher, respectively, than the actual payments received.

Under our current RVS billing system, the average Medicare reimbursement for low complexity procedures was $\$ 365.50$, increasing 1.7 -fold to $\$ 608.23$ when calculating the fee due under the proposed RBRVS billing model (see Table 16). Average Medicare reimbursement increased 2.8 -fold under the proposed billing model (from $\$ 543.53$ to $\$ 1,509.91$ ) for high complexity and 3.6-fold (from $\$ 1,690.21$ to $\$ 6,085.28$ ) for critical complexity management. The greatest increases in Medicare reimbursement between the current system and proposed billing model occurred as anesthetic management complexity increased.

\section{Discussion}

The commonly used RBRVS for valuing most medical work in the USA was adapted by us for billing anesthesia services. We propose a model for cross linking the ASA RVG to the RBRVS using current CPT codes across a wide variety of cases performed for inpatients and outpatients, adult and pediatric patients, and within both public and private facilities. It is important to note that this work was not a time-effort management engineering exercise, but an attempt to better define and capture the variance in perceived workload by senior anesthesiologists using the RBRVS system. We reviewed the work effort papers in the literature, much of which helped guide that part of our modeling. Several studies have characterized the work effort of anesthesiologists. Leedal and Smith identified three components of an anesthetist's workload (task demand, effort, and performance) and measured the mental and physical factors, which contribute to intraoperative work. ${ }^{14}$ Work by Weinger et al provided an objective measurement of workload, tasks, and vigilance among anesthesia personnel. ${ }^{15}$ More recently, workload was measured according to physiology-related (provider heart rate), psychology-related (self-assessment and observer rating), and procedure-related (response latency to an alarm light and workload density) parameters. ${ }^{8}$ In the end, we opted for the simplicity of utilizing the already well described base unit approach to physiological complexity, which is highly associated with task/work effort and provider stress.

Our proposed RBRVS billing matrix preserves the time aspect of anesthesia services and separates the anesthesia bill into component services (preoperative evaluation, intraoperative management, and postoperative evaluation), which are valued on par with other physician evaluation and management codes. Preoperative and postoperative evaluation charges were generated using current evaluation and management terminology, and charges for intraoperative management were generated according to complexity of care and time factors already utilized in the RBRVS. By incorporating an estimate of work value using evaluation and management terminology and intraoperative anesthetic management complexity, the anesthesiologist's work can now be better compared with other physician partners, especially important as our health care system evolves to an integrated system of hospitals and employed/allied multispecialty physician groups. Furthermore, within existing multispecialty groups, the ability to crosswalk from ASA RVS to an RBRVS value is critical. It will help to justify the commercial contract rate differentials that occur for anesthesia versus all other physicians in the same contract. Usually, all other physicians are paid in a multiple of MCR while anesthesiologists have an ASA RVU dollar value specially carved out, and this often leads to ostracism within the multispecialty group. This new model solves this simmering dilemma.

Our analysis was developed within only two health systems in a single geographic market that is served by a single large academic department of anesthesiology. A broader validation across multiple health systems and free-standing hospitals in multiple geographic areas is required.

An additional shortcoming of this proposed model is that it excludes billing for labor analgesia, as constant presence is not routinely provided, and a method for measuring the value of this service requires a different approach than procedural activities with constant presence. An additional study would be warranted evaluating procedural bills (eg, an epidural) 
plus stand-by services and carefully documented actual face time billed at an appropriate level of complexity. These data were not available for the current study. In addition, acute and chronic pain management is already on the RBRVS system and was not part of this study. Our analysis has a few additional limitations. The Medicare conversion factor for the billing period in Miami, ie, \$24.96/unit, was used. Our findings will be impacted by the wide range of conversion factors throughout the regions of the country. For example, the lowest mean commercial conversion factor in 2010 for the Western and Midwestern regions of the country was $\$ 54.67$ and $\$ 78.28$, respectively. ${ }^{11}$

One potential challenge in implementing a new model such as we propose is that changes would be required in anesthesia practice and workflow to meet the levels of required documentation for evaluation and management coding, such as inclusion of a chief complaint, history of present illness, medication review, and LOV (based upon medical decisionmaking). More descriptive terms would be needed for histories and physical examinations, which would be categorized as problem-focused, expanded problem-focused, detailed, or comprehensive. A review of systems would be required for all history and physical categories, except problem-focused histories, and a past medical, family, and social history would be required for the detailed and comprehensive history categories. However, the documentation of an assessment and anesthetic plan would remain unchanged. In the past, any required increase in documentation to achieve payment had been done $100 \%$. We believe that anesthesiologists will do as they have done in the past to adjust workflow to support documentation requirements. The increasing adoption and implementation of electronic health records, and the ease with which patient information can be transferred within a medical record, would facilitate the sharing of pertinent information between patient encounters.

After experience has been gained and the unknowns about documentation requirements have been discovered, the model can serve as a starting point to change how Medicare pays anesthesiologists. It is well accepted and previously well documented that there exists a marked difference between the ratio of MCR/UCR for anesthesia versus all other specialties. This analysis is further proof that such a disparity continues and is at odds with the value of the work performed by anesthesiologists. ${ }^{3,16}$ The fact that the new proposed RBRVS billing matrix differed by $3.0 \% \pm 1.34 \%$ from the expected private market reimbursement currently paid under the ASA RVG validates this new system as a good representation of the current workload and the total value of those services, although there was a large swing between low and critical anesthetic management complexity for what was most valued. The lower median and similar average suggest that some very difficult cases, that only anesthesiologists could manage, claim higher reimbursement but the total reimbursement remains constant. Most anesthesiologists would probably welcome higher payment and recognition for work that is not easily replaced by alternative providers. This new billing matrix does just that.

The savings in an ACO will be realized through collaboration of anesthesiologists with the other stakeholders to reduce specialty and hospital expenditures, hospital readmissions, hospital-acquired infections, adverse events, and lengths of stay. ACOs will allocate those savings to the providers based on their input, as determined by an RBRVS system. Anesthesiologists should view their unique billing system without an accepted crosswalk to a common measure of value, combined with a new joint accountability of physician groups in an ACO for patient outcomes and cost reductions, as a potential financial risk. Regardless of the future of ACOs, risk assuming population-based payments will proliferate, and the current model allows some basis to evaluate work on a common basis with a larger group using a singular methodology. Immediately, the current results support the carve-out for ASA RVG rate in commercial contracts at either two times the contracted MCR multiple or at the current commercial UCR. The ASA RVG differs from the RBRVS methodology used for all other medical services, and for surgical and diagnostic procedures. Advocating that anesthesiologists broaden their services and generate savings to an ACO by embracing perioperative medicine, establishing a preanesthesia clinic, prescreening patients, and reducing unwarranted testing is wise. ${ }^{17}$ However, recommendations to seek opportunities outside of the operating room never come with additional reimbursement as that work product is buried within base anesthesia units of each procedure. It serves as a counterproductive disincentive to engage where our services are most visible. The current ASA RVG reimbursement methodology is predominantly based in the operating room. ${ }^{17}$ Unless a new billing system is adopted, anesthesiologists may be in a disadvantaged position for upcoming negotiations and contracting for capitated payments and/or applied savings, which will take place as part of physician payment reform.

In summary, we propose a new method of billing and valuing anesthesia services that utilizes the common RBRVS, and which more fully reflects the level of medical decisionmaking and the complexity of care delivered. This new 
system will align anesthesia services with other physician services and allow for assessment of equivalent services across medical evaluations as well as surgical and diagnostic procedures. The proposed RBRVS model preserves the time unit component of the anesthesia service and divides the work input into component parts (preoperative evaluation, intraoperative management, and postoperative evaluation) that correlate with well established evaluation and management CPT codes. The proposed model places a significantly higher value on services that are of high complexity, and generates a wider spread of proposed reimbursement when considering high and low complexity cases. The model is validated by its applicability, its statistical validity across test sets and the practical result that yields almost identical reimbursement predicted under the new model compared with what commercial insurance currently pays under the existing ASA RVG methodology. We believe this is an important first step in moving anesthesia valuation firmly within the community of the overwhelming majority of physicians using the RBRVS and focuses higher reimbursement appropriately on the more complex care that less qualified alternative providers cannot easily do. We anticipate that this pilot study, in one health system, would outline the approach to a resource-based relative value system within the ASA. State societies would also be encouraged to consider regional differences to the RBRVS.

\section{Acknowledgment}

This research was supported by University of Miami, Department of Anesthesiology funds.

\section{Author contributions}

DRS helped design the study, conduct the study, analyze the data, and write the manuscript, and is the author responsible for archiving the study files. DAL, MMV, EAH, VB, REB, SMW, DJB, and KAC helped design the study, conduct the study, analyze the data, and write the manuscript. KA helped analyze the data and write the manuscript.

\section{Disclosure}

The authors report no conflicts of interest in this work.

\section{References}

1. McClellan M, McKethan A, Lewis J, Roski J, Fisher E. A national strategy to put accountable care into practice. Health Aff (Millwood). 2010;29:982-990.

2. Hsiao WC, Braun P, Dunn DL, et al. An overview of the development and refinement of the resource-based relative value scale the foundation for reform of US physician payment. Med Care. 1992;30: NS1-NS12.

3. Lubarsky D, Reves J. Using Medicare multiples results in disproportionate reimbursement compared with other physicians. J Clin Anesth. 2000;12:238-241.

4. Ginsburg P. Rapidly evolving physician-payment policy - more than the SGR. N Engl J Med. 2011;364:172-176.

5. Morton S, Kominski G, Kahan J. An examination of resource-based relative value scale cross-specialty linkage method. Med Care. 1994;32: 25-39.

6. Revicki D, Orkin F, Luce B, McMenamin P, Weschler J. Physician payment reform: anesthesiology as a case study. Anesthesiology. 1990;73: 760-769.

7. Abraham M, Ahlman J, Boudreau A, Connelly J, Evans D, Glenn R. CPT 2011 Standard Edition. Chicago, IL, USA: American Medical Association Press; 2010.

8. Weinger MB, Reddy SB, Slagle JM. Multiple measures of anesthesia workload during teaching and nonteaching cases. Anesth Analg. 2004;98(5):1419-1425.

9. Behrens V, Lubarsky DA, Vigoda MM, et al. A matrix billing model for determining complexity of care in the delivery of anesthesia. Abstract A365 presented at the American Society of Anesthesiologists Annual Meeting, October 15-19, 2011, Chicago, IL, USA.

10. Behrens V, Lubarsky DA, Vigoda MM, et al. A new framework for anesthesia reimbursement. Abstract A364 presented at the American Society of Anesthesiologists Annual Meeting, October 15-19, 2011, Chicago, IL, USA.

11. Byrd J, Singh L. Volume II: 2010 Commercial conversion factor survey results. Anesthesiology Newsletter. 2011;75(1):38-40.

12. Abraham M, American Medical Association. CPT 2010 Standard Edition. New York, NY, USA: American Medical Association; 2010.

13. Bodenheimer T, Berenson R, Rudolf P. The primary care-specialty income gap: why it matters. Ann Intern Med. 2007;146:301-306.

14. Leedal JM, Smith AF. Methodological approaches to anaesthetists' workload in the operating theatre. Br J Anaesth. 2005;94(6):702-709.

15. Weinger MB, Herndon OW, Zornow MH, Paulus MP, Gaba DM, Dallen LT. An objective methodology for task analysis and workload assessment in anesthesia providers. Anesthesiology. 1994;80(1):77-92.

16. Johnstone R, Hosaflook C. Financial impact if payers use Medicare rates. Anesthesiology. 2000;93:852-857.

17. Thilen SR, Sweitzer BJ. It is a good time to expand your circle! Anesth Analg. 2011;113(5):1279-1281.

\section{Publish your work in this journal}

The Journal of Multidisciplinary Healthcare is an international, peerreviewed open-access journal that aims to represent and publish research in healthcare areas delivered by practitioners of different disciplines. This includes studies and reviews conducted by multidisciplinary teams as well as research which evaluates the results or conduct of such teams or

\section{Dovepress}

healthcare processes in general. The journal covers a wide range of areas and welcomes submissions from practitioners at all levels, from all over the world. The manuscript management system is completely online and includes a very quick and fair peer-review system. Visit http://www.dovepress.com/testimonials.php to read real quotes from published authors. 